\title{
The clam sipho as indicator for growth indices in the soft-shell clam Mya arenaria
}

\author{
Frank Schäffer · Michael L. Zettler
}

Received: 1 July 2006 / Revised: 18 September 2006/ Accepted: 21 September 2006/ Published online: 24 October 2006 (C) Springer-Verlag and AWI 2006

\begin{abstract}
Due to the species' deep burrowing behaviour, growth parameters of the soft-shell clam Mya arenaria L. 1758 are difficult to estimate, especially in deeper habitats which are not directly accessible. In this study, we analysed 192 specimens of M. arenaria and found, contrary to results of most other studies that the sigmoid Gompertz growth model (GGM) is appropriate to describe the growth. Predictions from this model confirm the finding of a life span up to 8 years and as a consequence of this, a maximum shelllength of $60 \mathrm{~mm}$. Individual growth rates calculated from the first deviation indicate a nearly exponential growth in young individuals. The relationship between the clam sipho-width and age, shell-length and biomass conform to the GGM. This is a new approach to assess growth of $M$. arenaria and to solve practical problems that arise in field studies.
\end{abstract}

Keywords M. arenaria · Growth-indices . Sipho-width · Bertalanffy growth model . Gompertz growth model

Communicated by H.-D. Franke.

F. Schäffer $(\square)$

Institute for Biological Sciences-Marine Biology, Albert-Einstein-Straße 3, 18057 Rostock, Germany

e-mail: frank.schaeffer@uni-rostock.de

M. L. Zettler

Baltic Sea Research Institute Warnemuende,

Seestraße 15, 18119 Rostock, Germany

e-mail: michael.zettler@io-warnemuende.de

\section{Introduction}

The soft-shell clam Mya arenaria Linnaeus, 1758, originates from the Northwest Atlantic and invaded European waters a few hundred years ago (Strasser 1999). In the Baltic Sea, it occurs frequently in high abundance and biomass on sandy substrates (Kube 1996; Forster and Zettler 2004). In both autochthonous and allochthonous populations, growth patterns, life span (4-28 years) and maximum shell-length (27$135 \mathrm{~mm}$ ) vary considerably (e.g Feder and Paul 1974; Newell and Hidu 1982; Brousseau 1978; Maximovich and Guerassimova 2003). Moreover, former investigations showed that growth of $M$. arenaria is influenced by several factors, e.g. salinity, predation, pollution and seasonal variation (Appeldoorn 1981; Newell and Hidu 1982; Beal et al. 2001; Beal and Kraus 2002; Strasser 2002; Weiss et al. 2002). In the Baltic Sea growth of $M$. arenaria has been less studied. While some papers reported a linear age-size relationship along with spatial variation in growth (Kube 1996; Kube et al. 1996), Munch-Petersen (1973) showed an exponential growth pattern in a Danish estuary, and for the White Sea Maximovich and Guerassimova (2003) described growth of $M$. arenaria by a von Bertalanffy growth curve. It seems to be difficult to generalize growth patterns in M. arenaria due to varying methods of data collection, spatial and temporal variations of growth, recruitment and settlement as well as different environmental conditions. Whatever method is used practical problems arise, especially for investigations in deeper habitats. Monitoring sampling is accomplished through van Veen grap and occasionally siphos are cut off while the respective shells are not retrieved (Forster and Zettler 2004). This causes problems in 
estimating population structure, growth, biomass, production and filtration rates. In the present study we tested a new approach to estimate growth of $M$. arenaria in a typical brackish estuary and determined relationships, which allow for an estimation of bodymass and size of clams by using the size of the sipho.

\section{Methods}

A total of 192 individuals of $M$. arenaria were collected randomly from a brackish estuary in June 2003. The habitat called Schnatermann, is located at the Breitling, an estuary of the Warnow river, which flows into the Southern Baltic Sea near Rostock in Northeast Germany (Fig. 1). The salinity ranges between 8 and 12 PSU and the mean water depth from 0.1 to about $1 \mathrm{~m}$ except in the navigation channel. After treatment with magnesium chloride $(\mathrm{MgCl})$ to prevent retraction of the clam sipho, the entire sample was fixed with $4 \%$ formaldehyde. Shell-length, -width and -height were measured to the nearest $0.01 \mathrm{~mm}$ with a digital calliper. The sipho-width was estimated approximately $1 \mathrm{~mm}$ below the sipho-opening to the nearest $\mathrm{mm}$. Individual fresh-weight $(\mathrm{FW})$ was determined immediately after taking the individual out of the fixative. Dry-weight (DW) was determined after heating treatment $\left(60^{\circ} \mathrm{C}\right.$ for 10-12 h) and ash-weight (AW) after ignition for $12 \mathrm{~h}$ at $550^{\circ} \mathrm{C}$. Ash-free-dry-weight (AFDW $=\mathrm{DW}-$ AW) was calculated for each individual. All clams were weighed to the nearest $0.01 \mathrm{~g}$. Age was determined by counting surface growth lines. We assumed an annual origin of growth line during winter periods at least for the sampling area. However, particularly in older specimens counting growth lines proved to be difficult. Specimens were divided into age classes (1-year steps) and for each class means \pm standard deviations (SD) were calculated for shell-length (SL), -width (SW), -height (SH) and sipho-width (SWi). Individuals with values deviating from the mean of the respective age group by more than two fold SD were excluded from the statistical analyses (outliers). Tests of normality (Kolmogorov-Smirnov) and homogeneous variance (Levene's test) were carried out for SL, SW, SH and SWi, but failed for all $(P<0.05)$. Standard error, $F$ value, $R^{2}$ and significance $(P<0.01)$ have been given for the regression analyses. Because of allometric pattern in individual fresh-weight and shell-length relationship a specialised von Bertalanffy growth curve (sVBGF) with

$L_{\mathrm{t}}=L_{\infty} \cdot\left(1-\mathrm{e}^{-K \cdot\left(x-x_{0}\right)}\right)$

was performed by the method of the weighed least squares, where $L_{\mathrm{t}}$ is the shell-length $(\mathrm{mm}), L_{\infty}$ the theoretical asymptotic length $(\mathrm{mm}), K$ the growth rate, $x$ the age (years) and $x_{0}$ the age (years) of zero length. Because the residual variances were not constant around the independent (age) variable, weighed least squares estimate was applied (Neter et al. 1985). Thus, a Gompertz growth model (GGM) was performed with

$L_{\mathrm{t}}=L_{\infty} \cdot \mathrm{e}^{-\mathrm{e}^{\left(-K \cdot\left(x-x_{0}\right)\right)}}$

(unlike in the sVBGF, $x_{0}$ indicates the age at first inflexion point. All analyses were done using Statistica for Windows, Version 6, http://www.statsoft.com.

\section{Results}

The age structure of the individuals collected was relatively balanced (Fig. 2). Individuals with an age of 3 years were probably underrepresented; indicating
Fig. 1 Map of the study area with the "Schnatermann" location (inset above on the left); the black dot indicates the station where $M$. arenaria was collected in June 2003

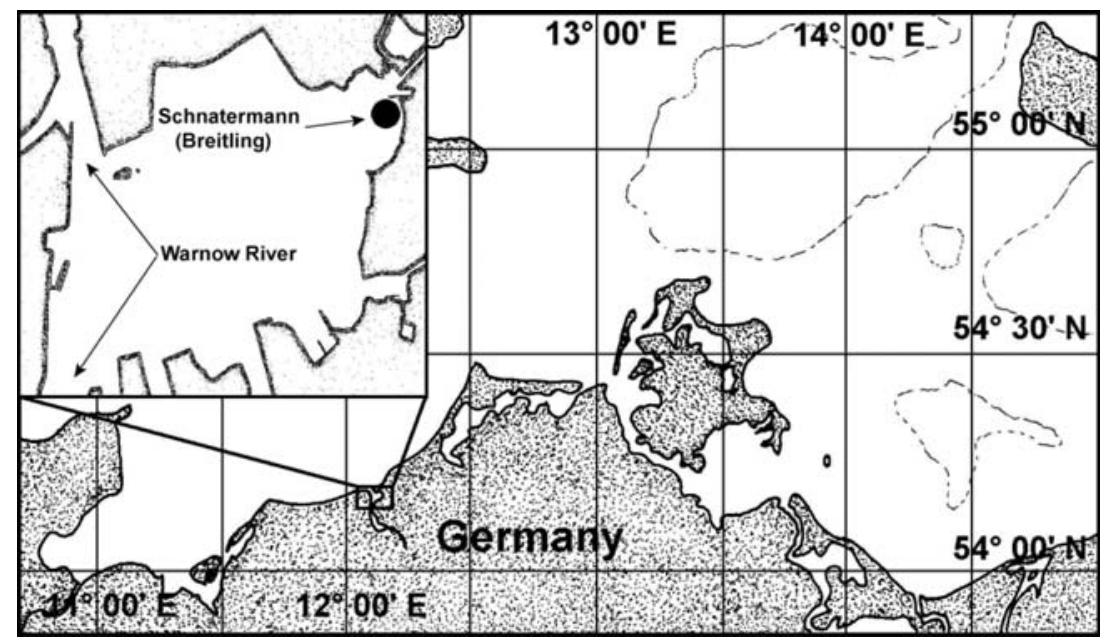


unsuccessful reproduction or settlement, and only one individual of 8 years was found. About $55 \%$ of the specimens were 4-5 years old, the 5-years group comprising about $35 \%$ of the specimens. A decrease in frequency was observed for individuals older than 5 years. The shell-length ranged from $9.05 \mathrm{~mm}$ at first year to $60.08 \mathrm{~mm}$ at 8 years. It should be noted that clams called " $x$ year" had $x$ annular rings. Both distribution and variances were not normal and homogeneous $(P<0.05)$, respectively for all tests. The age classes overlapped in shell-length (Fig. 3a) and the age-length relationship varied considerably within age groups, particularly in older individuals. Nevertheless, a Kruskal-Wallis ANOVA showed significant $(P<0.01)$ differences between age groups.

With increasing age the shell-length increment decreased with a sigmoid pattern (Fig. 3a). Therefore, a specialised von Bertalanffy growth curve (sVBGF) was calculated. The curve best fitting the data was obtained for $L_{\infty}=87.37 \pm 4.71(\mathrm{~mm}), K=0.16 \pm 0.01(\mathrm{~mm})$ and $x_{0}=0.66 \pm 0.48$ (years). The model predicts that shell growth starts between 0.18 and 1.14 years (Fig. 3a). This was contrary to the information provided by rings. Furthermore, the curve partly runs beyond the range of measured values (Fig. 3a). Application of the GGM yielded a better fit (Fig. 3a). Therein $L_{\infty}$ was estimated at $62.56 \pm 1.14(\mathrm{~mm})$ and was quite near to the observed maximum shell-length $(60.03 \mathrm{~mm})$. Table 1 gives detailed values of the estimated parameters. Moreover, the size specific growth curve $(\mathrm{d} x / \mathrm{d} y)$ of the GGM showed a more reasonable progression (Fig. 3b). The sVBGF size specific growth rate decreased exponentially with age, whereas the GGM predicts an exponential increase of growth in shell-length up to an age of 2.5 years and a subsequent linear decrease

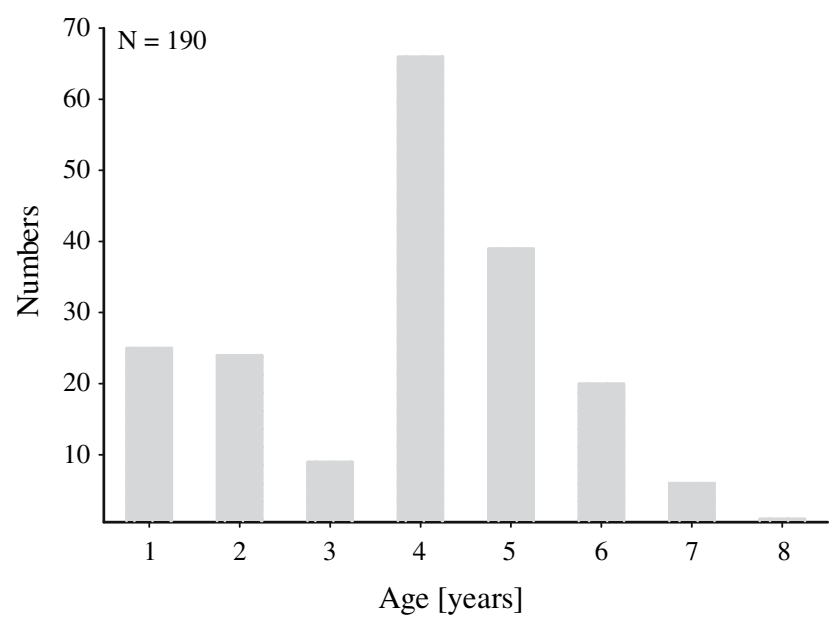

Fig. 2 Age structure of 190 specimens of M. arenaria
(Fig. 3b). With respect to the overall growth performance (for OGP $=\phi$ see Pauly (1979); Munro and Pauly (1983)), $\phi$ was determined at 3.1 (sVBGF) and 3.26 (GGM), respectively (Table 1 ). Compared to locations shown in Table $1, \phi$ indicates suitable conditions for $M$. arenaria at the study site. The threedimensional analysis of shell-length versus shell-height and shell-width indicates an isometric increase in both, volume and surface with $R^{2}=0.99$ (not shown by figure). Due to the relatively constant ratios between the different weight parameters (Fig. 6), shell-length (SL) shows an allometric relationship not only with freshweight (FW) (Fig. 4) but also with dry-weight (DW) as well as AFDW. Analogous relationships could be applied to shell-width (SW) vs. FW, DW and AFDW, and to shell-height $(\mathrm{SH})$ versus $\mathrm{FW}$, DW and AFDW, respectively. Consequently, a Gompertz growth curve could be calculated for body mass. As mentioned above there is an allometric relationship between shelllength and fresh-weight (Fig. 4) with

$\mathrm{FW}=a \cdot \mathrm{SL}^{\mathrm{b}}=1.55 \times 10^{-4} \cdot L^{2.87}$

Therein the standard error is \pm 0.00 for a and \pm 0.09 for $b$. From this equation we calculated the asymptotic fresh-weight $\left(W_{\infty}\right)$ by replacing SL with $L_{\infty}$, obtained from the GGM (Table 1; Fig. 3a). Then we replaced $L_{\mathrm{t}}$ and $L_{\infty}$ with $W_{\mathrm{t}}$ and $W_{\infty}$, respectively, from the GGM. Because of allometric relationship, we also had to use the condition factor $b=2.87$ from the obtained relationship between FW and SL. This ultimately leads to

$W_{\mathrm{t}}=W_{\infty} \cdot\left(\mathrm{e}^{-\mathrm{e}^{\left(-K\left(x-x_{0}\right)\right)}}\right)^{b}$

This equation indicates an only slight increase in freshweight during the first 2 years which was less than that of shell-length (compare Figs. 4, 5). As with individual shell-length, the values of individual fresh-weight overlapped widely between age groups. The mean ratios of FW/DW, FW/AFDW and DW/AFDW were largely homogeneous $(P>0.01$ for all $)$ over shelllength classes (Fig. 6a, b). The overall means of these ratios can be used as conversion factors (Fig. 6b): 1:2.5 for FW/DW; 1:2.9 for FW/AFDW; and 1:1.2 for DW/ AFDW.

The mean meat yield of individual shell-length ranged between 59 and $68 \%$ and thus proved to be relatively independent of shell-length. The sipho itself is a component of the soft tissue in bivalves and we found a relationship $\left(R^{2}=0.70\right)$ between sipho-width (SWi) and fresh-weight (FW) (Fig. 7a, b). The regression analysis based on sipho-widths centralized to 
Fig. 3 a Modelled growth curves (Gompertz and von Bertalanffy), and $\mathbf{b}$ size species growth rate curves of M. arenaria. Note Regression was weighed by age because of non-constant residual variance around the independent variable

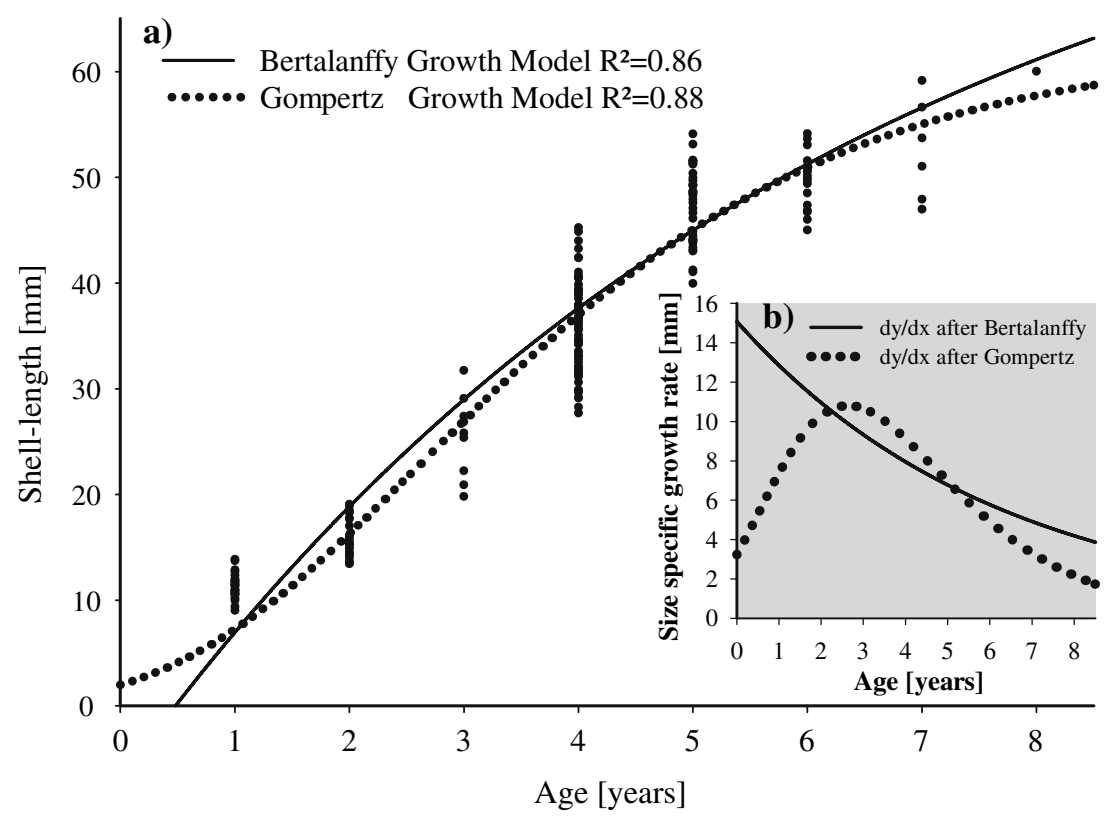

Table 1 Growth indices for $M$. arenaria from different locations

\begin{tabular}{lll}
\hline Location (author) (used model) & $K$ & $L \infty$ \\
\hline Sugatuck River, USA (Brousseau and Bagivlo 1987) (sVBGF) & 0.05 & 81.10 \\
Roskilde Fjord, Denmark (Munch-Peterson 1973) (sVBGF) & 0.30 & 60.10 \\
Kandalasksha Bay (Site A), Russia (Maximovich and Guerassimova 2003) (sVBGF) & 0.20 & 49.40 \\
Inner Oslo fjord, Norway (Winther and Gray 1985) (sVBGF) & 0.10 & 109.38 \\
Potato Island, Nova Scotia, USA (Appeldoorn 1983) (sVBGF) & 0.10 & 81.55 \\
Breitling, Baltic Sea, Germany (present study) (sVBGF) & 0.16 & 87.37 \\
Breitling, Baltic Sea, Germany (present study) (Gompertz) & 0.47 & 62.56 \\
\hline
\end{tabular}

$K=$ growth factor, $L_{\infty}=$ asymptotic shell-length $(\mathrm{mm})$, and OGP $[\phi]=$ overall growth performance after Munro and Pauly (1983)

$1 \mathrm{~mm}$ classes, showed for the range between 5 and $13 \mathrm{~mm}$ a pronounced relationship for FW vs. SWi, while adjacent ranges had to be omitted from the analyses (Fig. 7a). As FW is related to SL (Fig. 4), there is also a correlation between SWi and SL (Fig. 7b). The condition coefficient for SL versus SWi was close to one $(b=0.8)$, and this suggests a linear relationship between these parameters for SWi values ranging from 5 to $13 \mathrm{~mm}$ (Fig. $7 \mathrm{~b}$ ). The FW/SWi- and the SL/SWi-relationships are equivalent as indicated by $R^{2}=0.70$ for both.

\section{Discussion}

Many authors used external growth rings for estimating age of M. arenaria (Newcombe 1935; Brousseau 1979; Munch-Petersen 1973; Appeldoorn 1983; Kube 1996; Kube et al. 1996), though for some habitats no external growth rings for $M$. arenaria were found (e.g. Mead and Barnes 1903). But even though external growth rings are present, a relationship between age and growth rings is not mandatory as demonstrated by MacDonald and Thomas (1980) for the Prince Edward Island. Instead, they advise to use internal growth patterns of $M$. arenaria (MacDonald and Thomas 1980). In most cases growth rings were present and usable for estimating age (e.g. Brousseau and Baglivo 1988; Maximovich and Guerassimova 2003), but in Kandalashka Bay (White Sea) the first ring was not present in clams older than 2-years (Maximovich and Guerassimova 2003). In this study growth rings were present and assumed to be formed during the winter season. If the findings of Maximovich and Guerassimova (2003) also apply to the investigated area, we have to concede that the age of specimens may be underestimated. If this is the case, the given age structure (Fig. 2) may be affected. However, for the determination of growth curves this is negligible because only the parameter $x_{0}$ is changed as long as always clear growth rings were used. Nevertheless, we found small numbers of juvenile clams and a markedly decreasing 


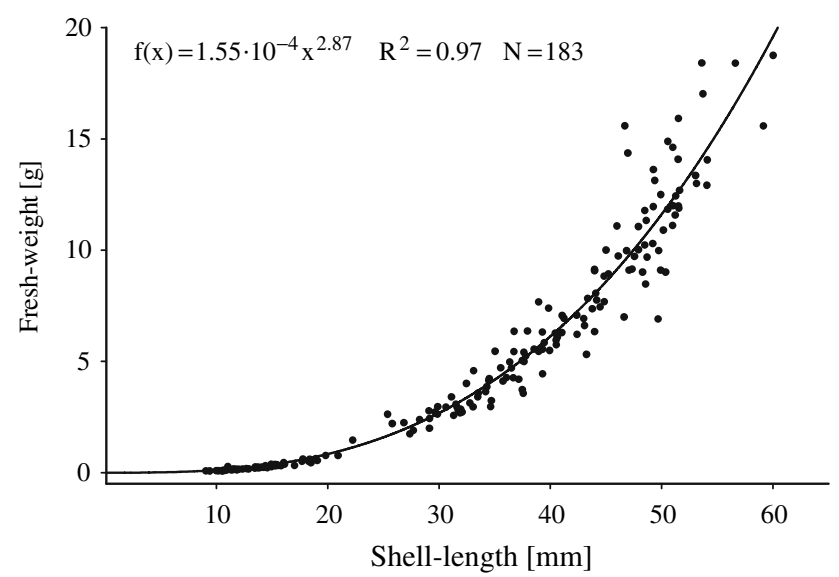

Fig. 4 Scatterplot with regression of individual fresh-weight versus shell-length for $M$. arenaria

abundance of individuals older than 4-years (Fig. 2). Probably a decline of recruitment, settlement and survival occurred either in the last season or the season before.

Clams living in experimental protected areas showed a higher survival compared to exposed areas (Beal and Kraus 2002) and reduced epibenthic predation could also positively affect the recruitment of bivalves (Strasser 2002). Generally, predation is a regulator for survival and settlement of juvenile clams, especially for M. arenaria (Günther 1992). In the Pomeranian Bay predation by fishes and sea ducks occur, especially on juvenile or small clams, because they are living in the dynamic surface of the sediment (Kube 1996). In dynamic sediments juvenile clams are moved to the sediment surface and thus are frequently exposed to predators. At the Schnatermann mainly epibenthic predators such as Crangon crangon and Hediste diversicolor occur (for clams $<2 \mathrm{~mm}$ ) as well as sea ducks which may be responsible for cropping on small clams and therefore reduce the abundance of juvenile $M$. arenaria. Furthermore, settlement on soft bottoms is determinate by the local hydrodynamic and topographic conditions (Günther 1992, and references therein), which are documented by bed load sediment transport and erosion for the Pomeranian Bay (Kube 1996). It cannot be ruled out that these unmeasured factors affect $M$. arenaria in the observed area. A constant mortality rate as assumed by Munch-Petersen (1973) as well as size- or age-dependent decrease of mortality with constant survival after maturation (Brousseau 1978) may not be evidenced due to the fact that age frequencies do not decrease at a constant rate in the observed area (Fig. 2). Indeed, decreasing number of individuals with increasing age may be interpreted as a constant mortality rate, but within the

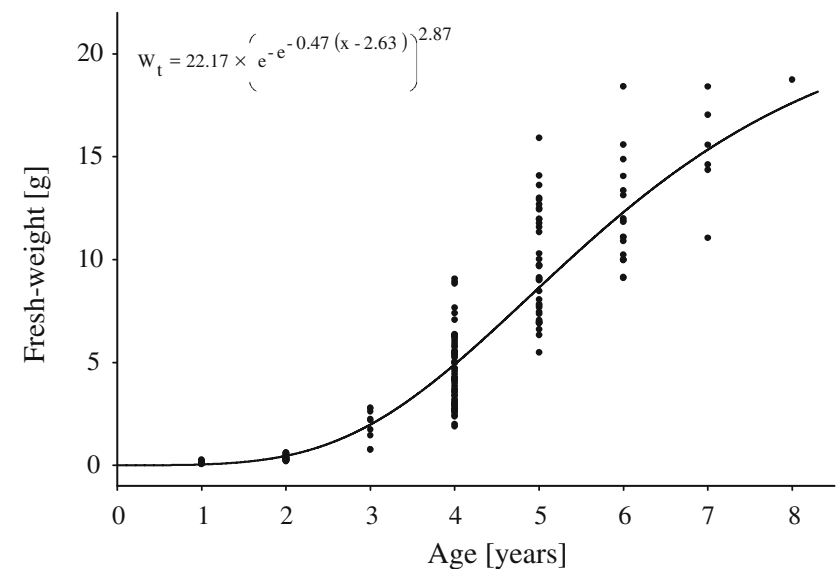

Fig. 5 Gompertz growth model $(G G M)$ for fresh-weight of $M$. arenaria. The parameters were estimated by computer regression (Statistica 6.0) as well as from data obtained from Figs. $3 \mathrm{a}$ and 5. Both estimates were equal. For details, see text

total age-range this is not proved. Rather we assume an age-dependent mortality rate after maturation as described by Günther (1992) and Maximovich and Guerassimova (2003).

The von Bertalanffy growth curve is a common tool to analyse growth data and growth rates. This model was copiously discussed before, and recently Urban (2002) pointed out that the generalised von Bertalanffy model (VBGF developed by Pauly (1979)) yields the best fit for data corresponding to his study. Using of the VBGF implicates the knowledge of the so-called surface factor $D$, which comprises net effects of anabolism and catabolism (e.g. Pauly 1979). Alternatively $D$ could theoretically be estimated from the shape of the shell but due to the irregular shape of the shell of $M$. arenaria difficulties arise and for this reason we did not test the VBGF in this study.

While past investigations in the Baltic Sea have shown linear growth of M. arenaria (Kube 1996), many researchers demonstrated isometric relationships between shell-length and fresh-weight (Feder and Paul 1974; Munch-Petersen 1973; Winther and Gray 1985). For cases of isometric relationships the specialised von Bertalanffy growth model (sVBGF) is recommended. It generates an asymptotic growth curve while the VBGF as well as the GGM reflect a sigmoid curve. The sVBGF suggests that most available energy is spent on producing new tissue or shell material during early lifetimes while with increasing age the available energy is dislocated to life-sustaining activities as indicated by the exponential decaying of the growth curve (Fig. 3). The raw data given in this study indicate a sigmoid growth-curve. Additionally, we found an isometric relationship ( $b=2.87)$ between shell-length and fresh- 
Fig. 6 Different weight ratios of 182 specimens of $M$. arenaria. a Means $( \pm \mathrm{SD})$ for different shell-length ranges, and $\mathbf{b}$ box plots over all shell-length ranges

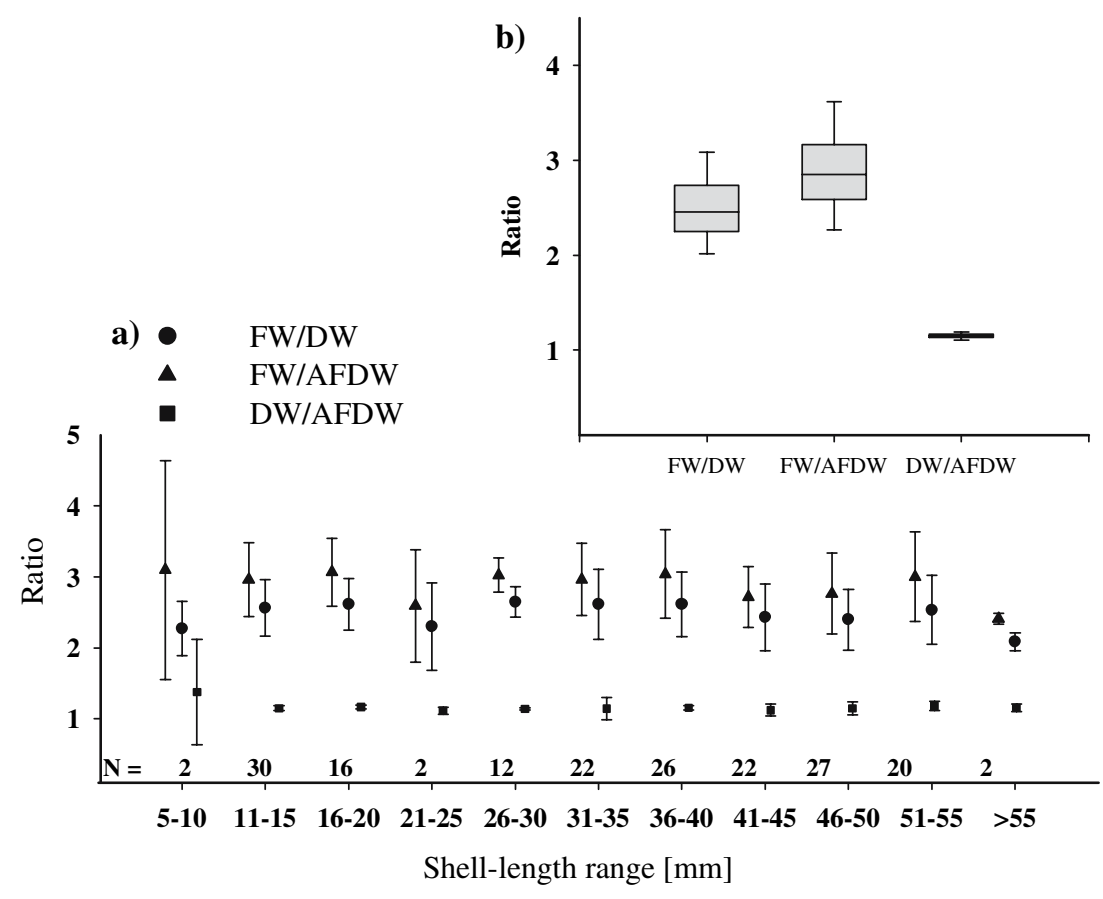

weight whereas the condition factor $b$ corresponds to values which were found at several locations (Feder and Paul 1974; Munch-Petersen 1973; Winther and Gray 1985). Hence, we tested the sVBGF as well as the GGM by means of analysing the residuals. However, the GGM predicts the asymptotic shell-length more reliably than the sVBGF does.

The maximum shell-length of $M$. arenaria varies considerably within its geographical distribution and ranged from 27 to $135 \mathrm{~mm}$ (Munch-Petersen 1973; Feder and Paul 1974; Brousseau 1979; Appeldoorn 1981, 1983; Winther and Gray 1985; Brousseau and
Baglivo 1987; Emerson et al. 1988; Maximovich and Guerassimova 2003). In this study the maximum shelllength was $60.03 \mathrm{~mm}$ and the asymptotic shell-length ranged from $62.56 \mathrm{~mm}$ for the GGM to $87.37 \mathrm{~mm}$ for the sVBGF. In dependence on the used model the theoretical age at which the asymptotic shell-length is achieved, is 8 (GGM) or 23 years (sVBGF). With respect to the possibility of underestimating age, the asymptotic shell-length arise at about 10 years in the GGM and is confirmed by the raw data. For the purpose of comparison we recalculated the asymptotic shell-length from data for the Pomeranian Bay ob-
Fig. 7 Relationships between sipho-width and a freshweight and b shell- length, respectively, of 138 specimens of $M$. arenaria (means $\pm \mathrm{SD}$ )
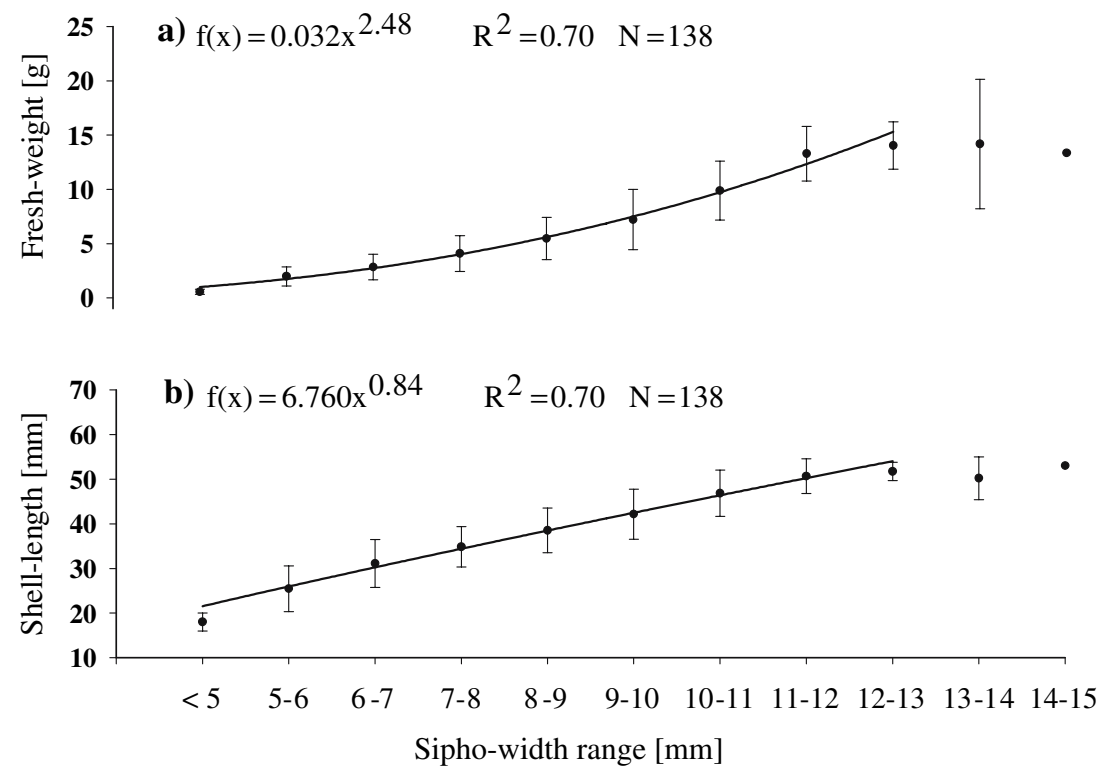
tained by Kube (1996) and computed a range from 24 to $50 \mathrm{~mm}$ for the maximum shell-length. This variability emphasises the influence of environmental factors on growth rates and maximal body size. Low salinity is identified as a main environmental factor related to growth, but recently the Chlorophyll a content in seston, stimulated by $N$-enrichment, was identified as main factor that influence growth rates of M. arenaria rather than low salinity ( $<20$ PSU) (Carmichael et al. 2004). However, the results of growth rates in form of both, the $K$ value and $\phi$, were relatively high compared to more marine habitats (Table 1) whereas the asymptotic shell-length was reached at lower values and at a minor age. Both, the $K$ value and $\phi$ may indicate the availability of better food supply and quality in the observed area.

With respect to growth analyses we present here a new method to estimate growth indices from the siphowidth of M. arenaria. To our knowledge, literature has never dealt with this approach before. The burrowing depth of sipho-exhibiting organism depends on the length of the sipho (Zwarts and Wanik 1989) and in general, larger infaunal species tend to bury deeper than smaller conspecifics. This has been shown for $M$. arenaria as well (Zaklan and Ydenberg 1997). Furthermore, the filtration rates of $M$. arenaria increased with both, increasing weight and shell-length (Riisgård and Seerup 2003). Consequently it is necessary that the rate of food intake is positively correlated to the rate of inflow. According to Poiseuilles's equation of flow through a tube, increased rates of inflow are only possible through either enlarging the pressure differential or enlarging the diameter of the tube. Enlarging the pressure differential is for $M$. arenaria only to a certain extent possible (Jørgensen and Riisgård 1988). Because of the physical exigency $M$. arenaria must be able to enlarge the diameter of the sipho. For this purpose the diameter of the sipho can be assumed to be proportional to the sipho-width of $M$. arenaria and hence we found a relationship between sipho-width and fresh-weight as well as shell-length.

Relationships between shell-length and fresh-weight may be usable to calculate production and biomass (Brey 2001) and our results are in agreement with this (Figs. 4, 5). If we succeed in establishing, for example, the relationship between sipho-width and shell-length to the relationship between shell-length and freshweight, we can estimate age, biomass etc. of the clam. This is important particularly for sites which are not directly accessible and whereby the use of a van Veen grab may cut off the clam siphos (Forster and Zettler 2004). Consequently and due to the deep burrowing behaviour of $M$. arenaria (up to $35 \mathrm{~cm}$ ) large and thus older individuals may be under-represented in samples. The present study has demonstrated how to alleviate the problem described above. Furthermore, a direct linkage between sipho-width and filtration rates of $M$. arenaria could be obtained through this method.

Acknowledgment The authors would like to express their gratitude to Jacob O'Mahony, University of Edinburgh, Scotland for correction and valuable comments on this manuscript. Also we would like to thank the editor-in-chief for time and effort he has spent on this paper. And we are indebted to Dr. Stefan Forster, University of Rostock, Germany for reviewing the last draft and his valuable comments on this manuscript.

\section{References}

Appeldoorn RS (1981) Response of soft-shell clam Mya arenaria growth to onset and abatement of pollution. J Shellfish Res 1:41-49

Appeldoorn RS (1983) Variation in the growth rate of Mya arenaria and its relationship to the environment as analyzed through principal components analysis and the Omegaparameter of the Von Bertalanffy equation. Fish Bull 81:7584

Beal BF, Kraus MG (2002) Interactive effects of initial size, stocking density, and type of predator deterrent netting on survival and growth of cultured juveniles of the soft-shell clam, Mya arenaria L., in eastern Main. Aquaculture 208:81-111

Beal BF, Parker MR, Vencile KW (2001) Seasonal effects of intraspecific density and predator exclusion along a shorelevel gradient on survival and growth of juveniles of the softshell clam, Mya arenaria L., in Main, USA. J Exp Mar Biol Ecol 264:133-169

Brey T (2001) Population dynamics in benthic invertebrates. A virtual handbook, version 01.2. AWI Bremerhaven http:// www.awi-bremerhaven.de

Brousseau DJ (1978) Population dynamics of the soft-shell clam Mya arenaria. Mar Biol 50:63-71

Brousseau DJ (1979) Analysis of growth rate in Mya arenaria using the Von Bertalanffy equation. Mar Biol 51:221-227

Brousseau DJ, Baglivo JA (1987) A comparative study of age and growth in Mya arenaria (soft-shell clam) from three populations in Long island Sound. J Shellfish Res 6:17-24

Brousseau DJ, Baglivo JA (1988) Life-Tables for two field populations of soft-shell Clam, Mya arenaria, (Mollusca, Pelecypoda) from Long-Island Sound. Fish Bull 86:567-579

Carmichael RH, Shriver AC, Valiela I (2004) Changes in shell and soft tissue growth, tissue composition, and survival of quahogs, Mercenaria mercenaria, and softshell clams, Mya arenaria, in response to eutrophic-driven changes in food supply and habitat. J Exp Mar Biol Ecol 313:75-104

Emerson CW, Minchinton TE, Grant J (1988) Population structure, biomass, and respiration of Mya arenaria on temperate sandflat. J Exp Mar Biol Ecol 115:99-111

Feder HM, Paul AJ (1974) Age, growth and size-weight relationships of the soft-shell clam, Mya arenaria, in Prince William Sound, Alaska. Proc Natl Shellfish Assoc 64:45-50

Forster S, Zettler ML (2004) The capacity of the filter-feeding bivalve Mya arenaria $\mathrm{L}$. to affect water transport in sandy beds. Mar Biol 144:1183-1189

Günther CP (1992) Settlement and recruitment of Mya arenaria in the Wadden Sea. J Exp Mar Biol Ecol 159:203-215 
Jørgensen CB, Riisgård (1988) Gill Pump characteristics of the soft clam Mya arenaria. Mar Biol 99:107-109

Kube J (1996) Spatial and temporal variations in the population structure of the soft-shell clam Mya arenaria in the pomeranian bay (Southern baltic sea). J Sea Res 35:335-344

Kube J, Peters C, Powilleit M (1996) Spatial variation in growth of Macoma balthica and Mya arenaria (Mollusca, Bivalvia) in relation to environmental gradients in the Pomeranian Bay (Southern Baltic Sea). Arch Fish Mar Res 44:81-93

MacDonald BA, Thomas MLH (1980) Age determination of the soft-shell clam Mya arenaria using shell internal growthlines. Mar Biol 58:105-109

Maximovich NV, Guerassimova AV (2003) Life history characteristics of the clam Mya arenaria in the White Sea. Helgol Mar Res 57:91-99

Mead AD, Barnes EW (1903) Observations on the soft-shell clam, Mya arenaria. Rhode Isl Comm Inld Fish 22:29-46

Munch-Petersen S (1973) An investigation of a population of the soft clam Mya arenaria L. in a Danish estuary. Medd Dan Fisk Havunders 3:47-73

Munro JL, Pauly D (1983) A simple method for comparing the growth of fishes and invertebrates. Fishbyte 1:5-6

Neter J, Wasserman W, Kutner MH (1985) In: Irwin RD (ed) Applied linear statistical models: regression, analysis of variance, and experimental designs, Homewood, IL

Newcombe CL (1935) Growth of $M$. arenaria in the Bay of Fundy region. Can J Res 13:97-137

Newell CR, Hidu H (1982) The effects of sediment type on growth rate and shell allometrry in the soft shelled clam Mya arenaria L. J Exp Mar Biol Ecol 65:285-295
Pauly D (1979) Gill size and temperature as governing factors in fish growth: a generalization of von Bertalanffy's growth formula. Ber Inst Meereskd Kiel 63:1-156

Riisgård HU, Seerup DF (2003) Filtration rates in the soft clam Mya arenaria: effects of temperature and body size. Sarsia $88: 415-428$

Strasser M (1999) Mya arenaria - an ancient invader of the North Sea coast. Helgol Wiss Meeresunters 52:309-324

Strasser M (2002) Reduced epibenthic predation on intertidal bivalves after a severe winter in the European Wadden Sea. Mar Ecol Prog Ser 241:113-123

Urban HJ (2002) Modelling growth of different developmental stages in bivalves. Mar Ecol Prog Ser 238:109-114

Weiss ET, Carmichael RH, Valiela I (2002) The effect of nitrogen loading on the growth rates of quahogs (Mercenaria mercenaria) and soft-shell clams (Mya arenaria) through changes in food supply. Aquaculture 211:275-289

Winther U, Gray JS (1985) The Biology of Mya arenaria (Bivalvia) in the eutrophic Inner Oslofjord. Sarsia 70:1-9

Zaklan SD, Ydenberg R (1997) The body size-burial depth relationship in the infaunal clam Mya arenaria. J Exp Mar Biol Ecol 215:1-17

Zwarts L, Wanik J (1989) Siphon size and burying depth in deposit- and suspension-feeding benthic bivalves. Mar Biol 100:227-240 